\title{
Legal move could open door to physics lab
}

Irwin Goodwin, Washington

High-energy physicists in the United States are hoping that a legal exemption could pave the way for construction of the proposed National Underground Science Laboratory.

Homestake, a disused gold-mine in Lead, South Dakota, owned by Canada's Barrick Gold, is the preferred site for the new laboratory.

But the company had said that without legal indemnity against future costs arising from environmental contamination at the site, it will flood the mine, eliminating its potential for use as a laboratory.

Just hours before Congress adjourned at the end of December, Senator Tom Daschle (Democrat, South Dakota) helped to arrange for the passage of a bill, the Homestake Mine Conveyance Act, that will remove Barrick Gold's legal liabilities and transfer the mine to the state of South Dakota. The legislation is likely to be signed into law shortly by President George W. Bush.

But officials at the National Science Foundation (NSF) - the agency most likely to pay for the laboratory - are unhappy that the exemption could land them with the bill for environmental problems at the site.

And the fact that it was won in large part through the efforts of Daschle, the majority leader in the Senate, could prove a mixed blessing for the project. Daschle is an early front runner for the Democratic nomination for the 2004 presidential election, and his role in winning the exemption has come under attack from Republicans.

Several scientific advisory committees have identified the Homestake mine as the most promising site for an underground US laboratory, which would be used to study neutrinos and other phenomena of interest.

John Bahcall, an astrophysicist at the

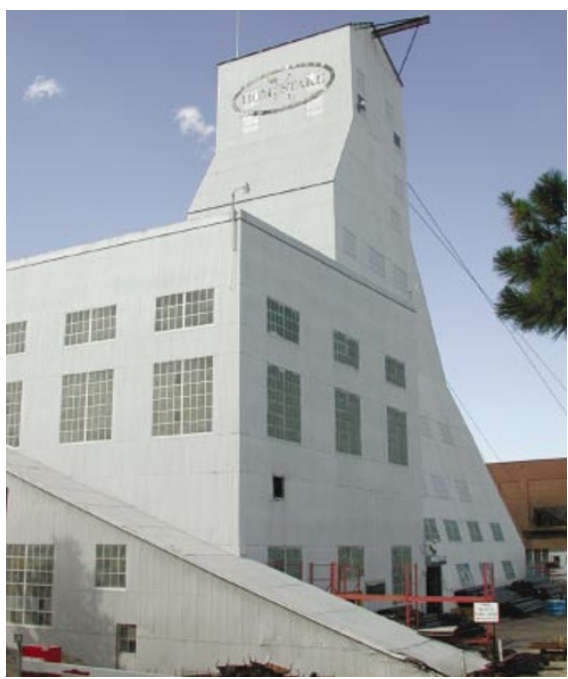

Homestake mine could house an underground lab where US physicists hope to strike gold.
Institute for Advanced Study in Princeton, New Jersey, and chair of one of these committees, notes that US researchers currently rely on overseas facilities for such work.

Bahcall says that researchers could "strike gold" at Homestake in such diverse fields as nucleon decay, solar neutrino measurements and the study of underground microorganisms. Reaching depths of 2,500 metres, Homestake is more than twice as deep as the overseas facilities, which means that it is even better protected from the cosmic rays that neutrino researchers seek to avoid by building their detection chambers underground.

The Department of Energy builds and administers most large physics facilities in the United States, but its current impoverishment has led researchers to look to the NSF as the most likely sponsor of the laboratory.

Robert Eisenstein, assistant director for mathematics and physical sciences at the NSF, agrees that Homestake is the best site for the laboratory. The NSF has reviewed the proposal twice and is considering spending $\$ 280$ million over five years on the project, although it has yet to make a final decision. It has been estimated that the lab might cost $\$ 1.2$ billion to build and operate for 10 years.

"The agency flatly refuses a stewardship role to protect the environment," says Eisenstein. "The project will need to take its place in a queue of proposals."

\section{Bushfires leave ecologists hot under the collar}

Peter Pockley, Sydney

The bushfires that have raged across New South Wales are fuelling arguments over the Australian government's approach to fire research.

The fires have consumed around half a million hectares of bush and forest, prompting calls from ecologists for more work on measures such as controlled burn, which, they say, could help to limit the bushfire problem.

Currently, the government spends around A\$2 million (US\$1 million) each year on bushfire research - half of which goes to the Commonwealth Scientific and Industrial Research Organisation (CSIRO), and the rest to universities.

The small team at the CSIRO is already claiming some success in garnering information that may have saved lives during this summer's fires. And the team's leader, Jim Gould, says that a six-year study in Western Australia has yielded better information on the rate that fires spread under different wind conditions.

But Phil Cheney, who founded the

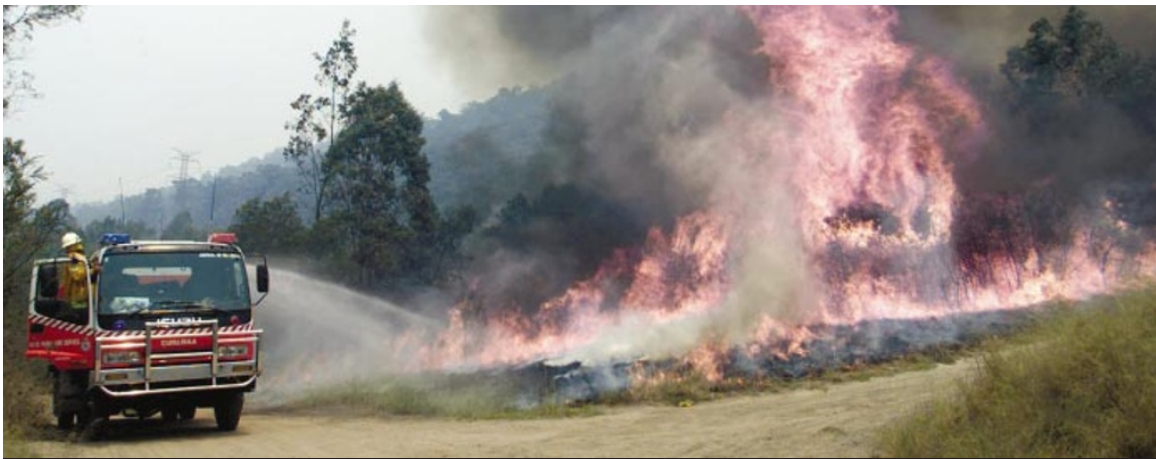

The burning issue: the devastation in New South Wales has led to calls for more fire research.

CSIRO's bushfire research team, has long campaigned for more fires to be lit under controlled conditions to reduce fuel levels in the bush. He points out that fire is natural in Australia, but that fuel now accumulates to dangerous levels so that the resultant fires "burn much more intensively".

Len Foster, chief executive of the Australasian Fire Authorities Council, says a concerted attempt to add to Australia's fire knowledge foundered last year, when a consortium led by Melbourne and Monash universities failed to win funding for a Cooperative Research Centre dedicated to the topic. Gould says that the project failed because too few state fire authorities offered to match the federal government's support.

Science minister Peter McGauran concedes that Australia could "make a bigger effort than we are at present" in bushfire research, and promises to revisit the merits of the project. 